\title{
Tackling Learning Difficulties With the Art of Dance and Movement in Preschool Age in the Greek School
}

\author{
Maria Sakellariou ${ }^{1}$, Panagiota Strati ${ }^{1} \&$ Polyxeni Mitsi ${ }^{1}$ \\ ${ }^{1}$ Department of Pre-School Education, University of Ioannina, Greece \\ Correspondence: Panagiota Strati, PhD, M.Ed., Department of Pre-School Education, University of Ioannina, Greece. \\ E-mail: panagiotastrati@yahoo.gr
}

Received: December 19, 2019

Accepted: January 13, 2020

Online Published: February 9, 2020

doi:10.5430/irhe.v5n1p1

URL: https://doi.org/10.5430/irhe.v5n1p1

\begin{abstract}
One of the main problems in the recent years that have been a matter of concern not only to teachers but also to other parties close to school life, is the treatment of children with learning disabilities. These difficulties act as an inhibiting factor in the educational progress of students and can even lead to social problems. This research work deals with the case study of students attending an integration section within a general class and their diagnosis' states: Mixed Developmental Disorders, Hyperactivity and Dyspraxia of subtle and agile mobility. The survey was conducted in a kindergarten of the Region of Epirus during the school year 2017-2018. Dance, movement, musical and kinetic games as forms of artistic expression according to the New Curriculum of the Kindergarten, were used as tools throughout all of the Cognitive Domains of the programme. Our purpose was the development of corporal consciousness, strengthening self-confidence and self-esteem, preventing and addressing mental, emotional and psychosomatic problems, reducing hyperactivity and dyspraxia of subtle and agile mobility. Through choreographies, musical performances, taking on a role or contacting diverse materials, the pupil is free to express himself/ herself and has the ability and flexibility to move any way he/she desires. Body movement, motion coordination, and body image thematics can help achieve the developmental goals.
\end{abstract}

Keywords: children with learning disabilities, mixed developmental disorders, subtle and agile mobility, dance, movement, musical and kinetic games

\section{Introduction}

Pre-school age is considered to be a period suitable for enhancing motion development (Cleland, Dwyer \& Venn, 2012. Telama, Yang, Leskinen, Kankaanpää, Hirvensalo, Tammelin, Viikari, Raitakari, 2014. Laukkanen, 2016). Children with learning disabilities are likely to exhibit disabilities on kinetics as well, such as deficient motion coordination, mobility ineptitude, balance problems, lack of rhythm as well as difficulties regarding subtle and agile mobility. Research has shown that dance may facilitate children with non-typical development express their emotions more efficiently, support them on cultivating their skills and help them evolve when facing learning difficulties (Jobling, Virji-Babul, Nichols, 2006· Ridler, 2014).

Creational mobility allows all children to participate, since each child approaches motion on different ways (Dow, 2010. Konstantinidou, Gregoriadis, Grammatikopoulos, Michalopoulou, 2014). Dancing is crucial to be incorporated within our curriculum if we are really eager to meet with our pupils' various needs. Positive effects on both impaired and non- impaired students, are present, concerning the inclusion of dancing, motion activities in general, within the educational process. This happens because the teacher provides each one of those students with a new alternative, allowing them to interact as well as express their ideas on their personal, unique way. Dance also facilitates an ostracism- free classroom, since inappropriate behaviour diminishes when all students have the opportunity to move around during the course. Moreover, dance provides a method of comprehensive assessment, since the chance of determining the comprehension of the contents by the pupils themselves, is given too (Skoning, 2008). "Dance comes by all means, beneficial to the pupils having difficulty to express themselves orally or in writing" and when creative motion aligns with the cognitive goals, a positive environment is formed (Skoning, 2008). A co- educational class goes when everyone can hold an equal share of the cognitive experience (Romita, 2016).

Dancing and kinetic games assist children on learning how to gain control of their body and develop the realization of spatial movement. "Creative motion is a form of art the means of which is the human body in motion itself" (Skoning, 
2008). Children operate their body by using all of the five elements of dance; relations, space, time, body consciousness and energy. Given these elements, children who have not been previously familiarized with bodily motion, are enabled to find all the guidelines necessary. "Creative motion provides children with opportunities to move in new ways and help them discover that more than one answers to a question, a puzzle or an assignment, exist" (Skoning, 2008).

The present paper is concerned with a study on the case of four pupils attending State General Kindergarten and their diagnosis reports: mixed developmental disorders, hyperactivity and subtle and agile mobility dyspraxia. The research was conducted in a Kindergarten of the District of Epirus during the 2017-2018 School Year, commencing on October 2017 and lasting until April 2018. It is an "intensive, holistic description and analysis of a circumscribed phenomenon" (Merriam, 2009), as it includes an intensive analysis of a group of pupils attending the General School, presenting motional coordination problems as well as learning disabilities on cognitive fields and who are likely to be excluded from the kinetic games and other classroom activities. Our purpose was to investigate whether:

Dance and kinetic games can help children

- acquire awareness of their body and motion, regarding dance.

- perceive their body as well as the changing of levels within space along with their typically developed classmates.

- associate the concept of rhythm to the ways of moving around space.

- realize the bodily expressional abilities.

- gain linguistic, mathematical and inter- personal as well as social development, skills.

Are toddlers with hyperactivity and motional coordination difficulties able to be taught folk dances?

\section{Methodology}

\subsection{Purpose of the Research}

The purpose of the current case study is to investigate whether a) pupils suffering mixed developmental disorders, hyperactivity and subtle and agile mobility dyspraxia can obtain skills by attending the general class and follow the Curricula respective to their education level and b) whether pupils who face learning difficulties benefit from the implementation of dance and kinetic curriculum, regarding each of the developmental sections.

\subsection{The Research Specimen}

Our specimen on the current case study consisted of four (4) pupils presenting mixed developmental disorders, hyperactivity and subtle and agile mobility dyspraxia, who were attending a general school. The intervention study was carried out into the general class with the collaboration of special and general education teachers.

\subsection{Methodological Approach of the Case Study}

In order for the goals of the survey to be achieved, a qualitative study of the cases was launched, emphasizing on the motion coordination abilities regarding pre-school age toddlers who were to be enrolled to the Elementary School the year after. Through a qualitative phenomenological example, the project formed a case study as such is defined by Creswell (Creswell, 2013) : "a borderline system (a case)" via detailed and profound collection of data, which includes various sources of information such as observation, debriefing, reports and documentation. Dance, motion, musical and kinetic games as a form of artistic expression according to the New Curriculum of the Kindergarten were used as tools throughout all the Educational Domains of the Curriculum (Institute of Educational Policy, Ministry of Educational and Religious Affairs, 2014). The validity of the selected data was, to a certain degree, ensured using the "Triangulation" method which, according to Hopkins (Hopkins, 1993) acts as a "reliability test". Three different sources, as well as a variety of methods (Yin, 2003), were used for the gathering of data; descriptive assessment of both, general and special educators, observations by the conductor of the research that were extracted from the daily logbook and observation keys in accordance to the kindergarten curriculum (2014) all of which assure for the intra-subjective testing of the audit findings. We were given the opportunity of advancing on a spherical evaluation of the case, as well as fully investigate and assess our conclusions.

\subsection{Restrictions on the Research}

All the participant pupils should be attending the general Kindergarten. With regards to their age they were to be enrolled to the Elementary School the following year (5 to 6 years of age). It was necessary that they possessed a Counseling Educational Centre (CEC/KE $\Sigma Y$ ) assessment report or one from the Medico-pedagogic Centre. We deem 
that a furthermore investigation in Kindergarten where typically and non-typically developed pupils are (inclusively) schooled, would be most legitimate on the purpose of generalizing our findings to a higher level of certitude.

\subsection{Data Analysis}

The method statement of the responses was carried out by using multitude and quotas for each of our inquiries. Despite the limited specimen, the Stuart-Maxwell statistical test was used, concerning paired variations expressed on over two categories, while the materiality level was determined to be equal to 0,05 . The analysis was conducted with the use of the Stata v. 11.0, software. An improvement of all childrens' performance was, with no exception, observed, on one or even two categories. Regarding the cases on which all four children showed improvement in the same manner, a statistical materiality on the improvement up to a value of $\mathrm{p}=0,0455$ occurred, according to the Stuart-Maxwell statistical test (a McNemar test extension). At this point it is essential to specify that the improvement applies for the whole of the investigatory inquiries on an itemized manner.

\section{Results}

The actualization of the purposes takes place on the current survey via three procedures: creation, presentation and responsiveness. Creation involves the utilization of elements regarding the art of dancing and motion by the cause of a stimulus, in order for the children to express their own ideas, their thoughts as well as their intentions. Presentation has to do with creating and demonstrating an artistic formation towards an "audience". This means the children while creating, they, simultaneously, act as viewers/ listeners of their own creation or that of their fellow students participating in the activity. Responsiveness accounts for not only how the children perceive and interpret what they just experienced but also what they see on others" "work" in the context of the creativity process as well as under the terms of presenting their artistic performances.

On the following table (Table 1), the initial evaluation of the four pupils after a month of observation is recorded. The data gathering occurs from the descriptive assessment of both, general and special educators, the observations of the conductor of the research that were extracted from the daily logbook as well as from the observation keys according to the kindergarten curriculum (October 2017).

Table 1. Distribution of pupils respective to their response towards the activities during the initial evaluation

\begin{tabular}{|c|c|c|c|}
\hline Initial Evaluation & Almost never & Occasionally & Frequently \\
\hline $\begin{array}{l}\text { Use of their body in order to demonstrate the motion of } \\
\text { waves, a cloud wandering in the sky. }\end{array}$ & 2 & 2 & \\
\hline $\begin{array}{l}\text { Create by corporal motion, symmetrical and } \\
\text { non-symmetrical shapes. }\end{array}$ & 4 & & \\
\hline Move around space in various patterns, imitating motion. & 2 & 2 & \\
\hline $\begin{array}{l}\text { Respond to specific movements, on pre- determined } \\
\text { sounds (one sound- one twist). }\end{array}$ & 3 & 1 & \\
\hline Move their arms so as to form a short story. & 4 & & \\
\hline $\begin{array}{l}\text { Separately move various body parts (their head acting as } \\
\text { a pencil that draws shapes). }\end{array}$ & 2 & 2 & \\
\hline Name various folk dances. & 4 & & \\
\hline Dance "Syrtos sta tria", "Hasapikos grigoros". & 3 & 1 & \\
\hline Take part in linguistic activities. & 1 & 3 & \\
\hline Comprehend short texts. & 2 & 2 & \\
\hline Express their feelings. & 2 & 2 & \\
\hline Comprehend space- time concepts. & 4 & & \\
\hline
\end{tabular}

At the beginning of the evaluation programme, all four pupils were practically always unable to move their arms so as to create a short story, were unable to form symmetrical and non- symmetrical corporal shapes through motion, were unable of naming any folk dances and failed at comprehending concepts of space- time. Only two of the four participants sparsely showed some sort of response to a few of the activities such as using their body in order to display 
movements, moving around space in various ways, expressing their feelings and comprehending texts. Regarding the linguistic activities, sometimes three (3) of the pupils responded, whereas the fourth almost never did so.

After the initial evaluation, the implementation of the following curriculum was determined:

We contributed to the materialization of goals using a variety of musical themes, on the purpose of the children starting to move around space while listening to them. They were asked to suggest ways in which they would move their body and we agreed with them on using various sound signals. We tried, in front of a mirror, with shapes that children could form with their body. We narrated stories the plot of which, children followed by motion. They had been moving around the whole space, getting around various positions- forward, back, sideways, diagonally- or staying still. We encouraged mobile expression on the purpose of expanding the children's imagination. We reached for the Sun and walked through the Dwarves' house. The children, as a team, moved objects from high to low and vice versa.

We scripted activities that involve basic mobility forms. We familiarized the children with the concept of successive motion and movement switching without in- between pauses. We beat the musical instruments on meters of quarters and verbally accompanied using narration, so the children were moving respectively to the appropriate rhythm. We utilized songs and poems that help children follow various beats thus coordinate their movements. We also used sound material containing significant volume changes. We mapped out activities which contribute at ameliorating movement precision and flexibility. We used sound stimuli in order to provoke agile reactions. By narrating stories we incited the children to use their body parts in fanciful ways. We enhanced their imagination through free kinetic improvisation.

We selected folk songs which toddlers can learn. We acted as role model, encouraging the children to take part in folk dances that required nothing but simple steps.

For the teaching of folk dances we also used

- A video presentation of the dance performed by one dancer only with measure (no music)

- A video presentation of the dance performed by one dancer without measure (but with music)

- A video presentation of the dance performed by a group of dancers (Traditional dances for C and D elementary school)

On the following table the final evaluation of the four pupils after six months of the curriculum implementation (April 2018), is catalogued.

Table 2. Distribution of pupils regarding their response towards the activities, during the final evaluation

\begin{tabular}{|c|c|c|c|}
\hline Final Evaluation & Almost never & Occasionally & Frequently \\
\hline $\begin{array}{l}\text { Use of their body in order to demonstrate the motion of } \\
\text { waves, a cloud wandering in the sky. }\end{array}$ & & 1 & 3 \\
\hline $\begin{array}{l}\text { Create by corporal motion, symmetrical and } \\
\text { non-symmetrical shapes. }\end{array}$ & & 1 & 3 \\
\hline Move around space in various patterns, imitating motion. & & 1 & 3 \\
\hline $\begin{array}{l}\text { Respond to specific movements, on pre- determined } \\
\text { sounds (one sound- one twist). }\end{array}$ & & 1 & 3 \\
\hline Move their arms so as to form a short story. & & 1 & 3 \\
\hline Separately move various body parts (their head acting as & & & 3 \\
\hline a pencil that draws shapes). & & 1 & \\
\hline Name various folk dances. & & & 4 \\
\hline Dance "Syrtos sta tria", "Hasapikos grigoros". & & & 4 \\
\hline Take part in linguistic activities. & & 1 & 3 \\
\hline Comprehend short texts. & & 1 & 3 \\
\hline Express their feelings. & & & 4 \\
\hline Comprehend space- time concepts. & & 1 & 3 \\
\hline
\end{tabular}


At the completion of the curriculum, dance and kinetic games proven to be of significant assistance to the team (three of the pupils moved to the "frequently" column while the fourth to the "occasionally" column) regarding the use of their bodies to display movements, move around space in various ways and react on predefined sounds, move their heads as a pencil which is drawing a variety of imaginary shapes, comprehend small texts. An improvement was observed to all of the four pupils $(\mathrm{P}=0,1653)$. It was, additionally, established that the pupils, after six months of participating in the curriculum, were able to form symmetrical and non- symmetrical bodily shapes by motion, move their arms and make up a story, express their feelings, take part in linguistic activities and comprehend space/time concepts (improvement up to $\mathrm{P}=0,1353$ ). Regarding the folk dances, a remarkable amelioration was recorded for the whole team $(\mathrm{P}=0,0455)$. It is essential to point out that no one of the participants lagged behind to the "almost never" column.

\section{Discussion and Conclusions}

Dancing and kinetic games within the Kindergarten contribute to children with non typical development, acquire artistic experiences which shall help them evolve their sensory literacy offering them, in turn, alternative, creative ways of communication. It is important that both, the participation of every single child as well as collegiality are promoted. The educator, acting on the context of the cognitive unit in which dancing and kinetic games belong, has to introduce into the Inclusive Class, a variety of symbolisms and encourage children to give shape to emotions, ideas and thoughts in order for them to be able to express themselves (Institute of Educational Policy, Ministry of Educational and Religious Affairs, 2014).

Our evaluation project aimed at the gathering and recording of data that demonstrate the children's learning as they involve themselves on a series of artistic expression activities. Under these terms, the educators would debate with the pupils on the experiences they had been collecting. They had been observing and recording the level of the pupils' participation in the kinetic activities and dancing, their ability of expressing their thoughts, emotions and ideas, their response towards the stimuli they had been offered, as well as their capability of interacting. All of these gathered elements were deployed towards the selection and planning of activities to come.

We discovered that dance and kinetic games can definitely be used as tools throughout the whole range of cognitive domains of the curriculum and help non- typically developed children comprehend topics stemming from the domains of language, personal and social development and mathematics (Evangelopoulou, 2014). With the toddlers participating in dancing activities and kinetic games, their linguistic skills are cultivated, since they are provided with the opportunity to express and communicate. Chances are also offered on the field of developing their mathematical abilities such as succession, counting, duration and patterning, the concepts of space and time as well.

Addressing the difficulties of non-formal children involved in our research was a complex and long-term process aimed at both developing or improving the skills of children associated with school learning and on the other hand to alleviate the emotional difficulties they face. Concerning spacetime concepts, dance and kinetic games helped children to be placed in space and to understand directions such as left / right. Orientation problems also affect the understanding of other concepts, such as up / down, high / low, deep / shallow, even the position and role of the player in the various group games, so usually children with learning disabilities do not participate. We managed to reduce the orientation problems with kinetic games and dance.

Therefore, the involvement of children with mixed developmental disorders, hyperactivity and dysfunction of gross and delicate mobility with music and dance (traditional play songs, group activities, musical instrument learning) contributed to the development of kinetic, linguistic, social, emotional and cognitive skills as a valuable means of early intervention. Like Storr (1992), we emphasized the emotional value of music and argued that the main reason for its existence is interpersonal communication. Music and dance caused strong emotional excitement and contributed to the emotional development of young children.

Interventions improve the quality and quantity of basic skills. Practices that enhance flexible and functional interaction in the natural environment with a small group of peers and adults have been shown to promote children's communication and cognitive development (Hebbeler \& Spiker, $2016 \cdot$ Kaiser \& Trent, 2007). Children with disabilities have a problem interact with their peers and adults and need to be taught social skills such as communication, problem solving, and decision making through kinetic games, role-playing games, and dance. Studies involving children from 3 to 5 years old have shown that social intervention for skill development can positively increase social interactions and reduce behavior problems (Vaughn, Kim, Sloan, \& Sridhar, 2003 - Sakellariou, Strati, \& Anagnostopoulou, 2019). The same conclusion is reached by our research taking into account the views of the school teachers through their experience and the results of the educational program. 
In our interventional project we implemented a contemporary curriculum which assists on differentiation of learning statuses. The development of versatile curricula which are based on the differentiation of learning statuses is a sheer necessity for a modern School (Callan, 201). Differentiation requires the existence of a flexible curriculum which is constantly put under modification so as to meet every single pupil's personal needs (Griffin, Shelvin, 2011). Differentiating learning experiences assist on the achievement of all children's attendance to the General School and their coeducation within it (Mumford, Chandler, 2009). However research data revealed the limited use of differentiated teaching by the majority of Kindergarten teachers during the educational process and ultimately the adoption of traditional forms of instruction (Sakellariou \& Mitsi, 2019).

Katz advocates that a contemporary curriculum should include knowledge, skills, predisposition (curiosity, creativity) and emotions (confidence, safeness) (Ambartzaki, Kypriotaki, 2010). The need for re-education of the teachers on issues concerning co-inclusive education is the desideratum on numerous research studies (Malikiosi- Loizou, 2003. Padeliadu, Patsiodimou, 2000· Parker, McHatton, Allen, Rosa, 2010).

A re-designed general School curricula for implementation:

- Shall back the educators in ways, techniques and strategies in order for them to substantially teach children with non- typical development, within the general class.

- Shall take into account all of the parameters that are involved with the children's socialization and emotional evolution.

Shall promote the participation of the children themselves in the learning process.

Schools must be prepared both to accommodate students with different needs and to behave in a preventive manner to eliminate barriers and participate fully (Sakellariou, Strati, \& Konsolas, 2018). Schools need to adopt integration features while at the same time being ready to dismantle the mechanisms and practices that lead to exclusion (Forlin, 2013). Therefore, it involves revising integration from the perspective of a school-wide approach that the school environment will make changes so that they are friendly to all children (Forlin, Chambers, Loreman, Deppeler, \& Sharma, 2013).

Furthermore, it is important the continuous training of teachers on Differentiated Instruction ssomething that are willing to attend it and the provision of appropriate supporting equipment (Rodriguez, 2012; Sakellariou \& Mitsi, 2017). The school, with the implementation of innovations and alternative teaching approaches, can work constructively in addressing the social and pedagogical challenges in order to make the most effective contribution to teaching and learning students (Sakellariou \& Mitsi, 2017· Sakellariou, Mitsi \& Konsolas, 2018).

Conclusively, non- typically developed pupils are quite possible to experience marginalization within a class. The current study establishes all the advantages ensued from the admission into a general class of children who undergo learning difficulties and exhibit mixed developmental disorders, as well as from the implementation of curricula designed for all children without exception. Toddlers who suffer such difficulties may indeed, develop significant skills by dancing and motion, when they are provided with suitable opportunities. Similar results have been demonstrated by other studies (Romita, 2016). Educators, is necessary to offer chances for those students, by diversifying learning and making the most out of their assets. Many of us deem that dance and creative mobility are the elements absent from the educational process. We are most keen on involving ourselves with further investigation on co- inclusive classes.

Funding: This research received no external funding.

Acknowledgments: This research did not receive any specific grant from funding agencies in the public,commercial, or not-for-profit sectors.

Conflicts of Interest: The authors report no conflict of interest.

\section{References}

Ambartzaki, M., \& Kypriotaki, M. (2010). Differentiating cognitive experiences within the mainstream Kindergarten on the purpose of integrating children who face handicaps in life and learning. Early interventionInterdisciplinary Dimension. Athens, "Pedio" publications.

Callan, L. (2013). A Case Study Examining the Inclusion of Children with Special Educational Needs in a MainstreamPrimary School. Thesis. Trinity College: Dublin. Retrieved 20 April 2019, from https://docplayer.net/19665688-A-case-study-examining-the-inclusion-of-children-with-special-educational-nee ds-in-a-mainstream-primary-school-louise-callan.html 
Cleland, V., Dwyer, T., \& Venn, A. (2012). Which domains of childhood physical activity predict physical activity in adulthood? A 20-year prospective tracking study. British Journal of Sports Medicine, 46(8), 595-602. https://doi.org/10.1136/bjsports-2011-090508

Creswell, J. W. (2013). Qualitative inquiry and research design: Choosing among five approaches. Los Angeles, CA: Sage.

Dow, C. B. (2010). Young children and movement: The power of creative dance. Young Children, 65(2), 30-35.

Evangelopoulou, P. (2014). A case study on Maths Dance: The impact of integrating dance and movement in maths teaching and learning in preschool and primary school settings. June 2014. DiVA.

Forlin, C., Chambers, D., Loreman, T., Deppeler, J., \& Sharma, U. (2013). Inclusive Education for Students with Disability. A review of the best evidence in relation to theory and practice. The Australian Research Alliance for Children and Youth (ARACY).

Forlin, C. (2013). Issues of Inclusive Education in the 21st Century. Journal of Learning Science, 6, 67-81.

Griffin, S., \& Shelvin, M. (2011). Responding to Special Educational Needs: An Irish Perspective. Dublin: Gill and MacMillan.

Hebbeler, K., \& Spiker, D. (2016). Supporting youg children with disabilities. The Future of Children, 26, 2.

Hopkins, D. (1993). A teacher's guide to classroom research (2nd ed.). Buckingham- Philadelphia: Open University Press.

Institute of Educational Policy, Ministry of Educational and Religious Affairs. (2014) National Curriculum for the Kindergarten. Retrieved 20 April 2019, from http://repository.edulll.gr/edulll/handle/10795/1859

Jobling, A., Virji-Babul, N., \& Nichols, D. (2006). Children with down syndrome: Discovering the joy of movement. Journal of Physical Education, Recreation \& Dance, 77(6), 34-38, 53-54.

Kaiser, P. A., \& Trent, J. A. ( 2007). Communication Intervention for Young Children with Disabilities: Naturalistic Approaches to Promoting Development in Handbook of Developmental Disabilities. New York: Guilford Press.

Konstantinidou, E., Gregoriadis, A., Grammatikopoulos, V., \& Michalopoulou, M. (2014). Primary physical education perspective on creativity: The nature of creativity and creativity fostering classroom environment. Early Child Development and Care, 184(5), 766-782. https://doi.org/10.1080/03004430.2013.818989

Laukkanen, A. (2016) Physical Activity and Motor Competence in4-8-Year-Old Children. Results of a Family-BasedCluster-Randomized ControlledPhysical Activity Trial. Studies in Sport, Physical Education and Health 238. University of Jyväskylä.

Malikiosi- Loizou, M. (2003). A critical view on empathy. Psychology, 10, 295-307.

Merriam, S. B. (2009). Qualitative research: A guide to design and implementation. SanFrancisco, CA: Jossey-Bass.

Mumford, V. E., \& Chandler, J. P. (2009). Strategies for supporting inclusive education for students with disabilities. Strategies: A Journal for Physical and Sport Educators, 22(5), 10-15. https://doi.org/10.1080/08924562.2009.10590834

Padeliadu, S., \& Patsiodimou. A. (2000). Views and motivation of educators regarding their retraining on Special Education. Proceedings of the VI Conference of the Cyprus Pedagogical Association "Modern Research on the Education Sciences" (pp. 75- 84). University of Cyprus, Republic of Cyprus, 2000.

Parker, A., McHatton, P. A., Allen, D., \& Rosa, L. (2010). Dance lessons: Preparing preservice teachers for coteaching partnerships. Action in Teacher Education, 32(1), 26-38. https://doi.org/10.1080/01626620.2010.10463540

Ridler, R. (2014). Dance: Learning movements to break through barriers. Physical \& Health Education Journal, 80(3), 24-26.

Rodriguez, A. (2012). An Analysis of Elementary School Teachers' Knowledge and Use of Differentiated Instruction. United States: Olivet Nazarene University.

Romita, F. (2016). Integrating dance for students with learning disabilities. Master of Teaching. Department of Curriculum Teaching and Learning Ontario Institute for Studies in Education, 2016. University of Toronto.

Sakellariou, M., \& Mitsi, P. (2017). Investigation of the attitudes and beliefs of prospective Kindergarten and Primary school teachers on the implemented functionality of Differentiated Teaching within the framework of Teaching 
Practice. Paper presented at the International Conference titled: Differentiation of instruction for teachers' professional development and students' success, May, 26-27, 2017, Nicosia, Cyprus.

Sakellariou, M., \& Mitsi, P. (2019). Prospective Kindergarten and Primary school teachers' attitudes and beliefs on Differentiated Teaching during their Teaching Practice. Journal of Advanced Research in Social Sciences, 2(2), 01-28. https://doi.org/10.33422/JARSS.2019.05.05

Sakellariou, M., Mitsi P., \& Konsolas, E. (2018). Investigating the factors of difficulty in the Implementation of Differentiated Instruction in Greek Primary Education. $5^{\text {th }}$ International Conference on Research in Behavioral and Social Science. Spain | Barcelona| December 7 - 9, 2018.

Sakellariou, M., Strati, P., \& Anagnostopoulou, R. (2019). The role of social skills throughout inclusive education implementation. East African Scholars Journal of Education, Humanities and Literature, 2(10), 633-64. https://doi.org/10.36349/EASJEHL.2019.v02i10.22

Sakellariou, M., Strati, P., \& Konsolas, E. (2018). Exploring the Attitude of Greek Kindergarten and Primary School Teachers towards Inclusive Education. Journal of Advanced Research in Social Sciences, 1(1), 43-60. https://doi.org/10.33422/JARSS.2018.04.25

Skoning, S. N. (2008). Movement and dance in the inclusive classroom. Teaching Exceptional Children Plus, 4(6).

Storr, A. (1992). Music and the mind. London: Harper Collins.

Telama, R., Yang, X., Leskinen, E., Kankaanpää, A., Hirvensalo, M., Tammelin, T., ... Raitakari, O. T. (2014). Tracking of physical activity from early childhood through youth into adulthood. Medicine \& Science in Sports \& Exercise, 46(5), 955-962. https://doi.org/10.1249/MSS.0000000000000181

Traditional dances for C and D elementary school. Retrieved 20 April 2019, from http://www.pi-schools.gr/lessons/gymnastics/ypost_yliko/paradosiakoi/xoros7_mousiki.html

Vaughn, S., Kim, A., Sloan, M. C., \& Sridhar, D. (2003). Social Skills Interventions for Young Children with Disabilities: A Synthesis of Group Design Studies. Remedial and Special Education, 24, 2-15.

Yin, R. K. (2003). Case Study Research-Design and Methods: Applied Social Research Methods (Vol. 5, 3rd ed.). Thousand Oaks, California, Sage Publications. 